\title{
Analysis of lighting withstand level and flashover phases of tower double circuit transmission line
}

\author{
Dongmin Xi, Dan Zhang and Jiachen Liu ${ }^{\mathrm{a}}$ \\ Inner Mongolia University of Technology, Electric power college,13674821501,China
}

\begin{abstract}
The overhead transmission lines stretching thousands of miles, accounted for a large part of power system, and lightning transmission line fault is the most main form of power system fault. In order to reduce the transmission corridor area, double circuit and even more loop transmission lines were more and more adopted, and therefore the tower is higher and higher. And the higher the tower, the greater the possibility of being struck by lightning. Thus it is very necessary to research and analyze the tower double circuit transmission line. The model of canal $110 \mathrm{kV}$ substation was established and the lighting withstands level and flashover phases were analyzed through the electric transient simulation program ATP-EMTP. Keywords: tower double circuit; flashover phases; ATP-EMTP; lighting withstand level.
\end{abstract}

\section{Introduction}

Lightning is a spectacular natural phenomenon but common, but due to its great energy, when lightning occurs, it will produce a great impact on the safety of human life and the normal operation of our daily life and production of telecommunications, electricity, construction and other industries. Lightning over-voltage is the most main reason of power system lightning trip and insulation failure[1].

The rate of transmission line tripping accidents caused by lightning is more than $50 \%$ in Japan, Sweden, the United States, Canada and some other countries. In China, lightning trip rate can reach $70 \%$ in the areas of Frequent lightning activity and high soil resistivity, it has reached $40 \%$ even in the areas of ideal soil resistivity and flat terrain. So it is necessary to research on the lightning activity and its prevention.

In the early time, tower double circuit transmission is mainly used in $500 \mathrm{kV}$ and above grade EHV (Extra High Voltage)transmission lines, with the development of smart grid, power grid at all levels are in continued development, and the applications of double-circuit transmission line towers in $110 \mathrm{kV}$ and $220 \mathrm{kV}$ power systems are also increasing. With respect to $500 \mathrm{kV}$ and above EHV, the analysis of tower double circuit transmission on $110 \mathrm{kV}$ and $220 \mathrm{kV}$ is relatively less[2]. Due to the erection of the two-circuit transmission lines on the same tower, it is easy to cause lightning trip in both lines and bring greater threat to the safe operation of the power system. Therefore, the research of lightning flashover situation of tower double circuit transmission lines is of practical significance.

a Corresponding author : 964056933@qq.com

(C) 2016. The authors - Published by Atlantis Press 


\section{Simulation models}

\subsection{Lightning current source}

The $2.6 / 50 \mu$ s standard lightning surge is adopted the simulation, there are two types of impact current source in ATPDraw, which are Surge type and Heidler type, Heidler type 15 is adopted in this paper. Lightning channel impedance is connected in parallel with the current source, the lightning current model is shown in Figure 1.

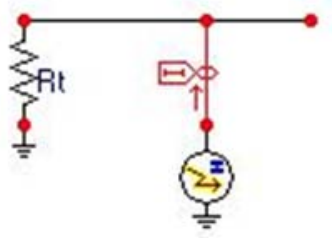

Figure 1. Model of lighting current source.

\subsection{Insulator string}

Canal $110 \mathrm{kV}$ substation's double circuit transmission line use the insulation method of balanced insulation. Each phase have adopted the insulator string consisting of seven disc-shaped suspension glass insulator, $50 \%$ flashover voltage of the insulator string is $776 \mathrm{kV}$. Considering the advantages and disadvantages of the various methods, the regulation method has the most simple structure and practical engineering operation basis, therefore the regulation method is adopted to judging insulator's flashover[3].

Insulator's flashover is simulated by gap switch in ATPDraw. This switch is always turned on at steady-state, switch is closed when the absolute value of the voltage across the switch exceeds U50\%, which represents the insulator's flashover.

\subsection{Transmission line}

LCC multiphase coupling line J. Marti model is selected to simulate the transmission line, Since the coupled voltage between the wires and the ground wires has been automatically accounted, there is no need to take into account in simulation. Canal $110 \mathrm{kV}$ substation's transmission line and location arrangement simulated by LCC are shown in Figure 2, a total of eight phases, where phase 1 to 3 are the phase conductors of circuit I, phase 4 to 6 are the phase conductors of circuit II, and phase 7 and 8 are the ground wires.
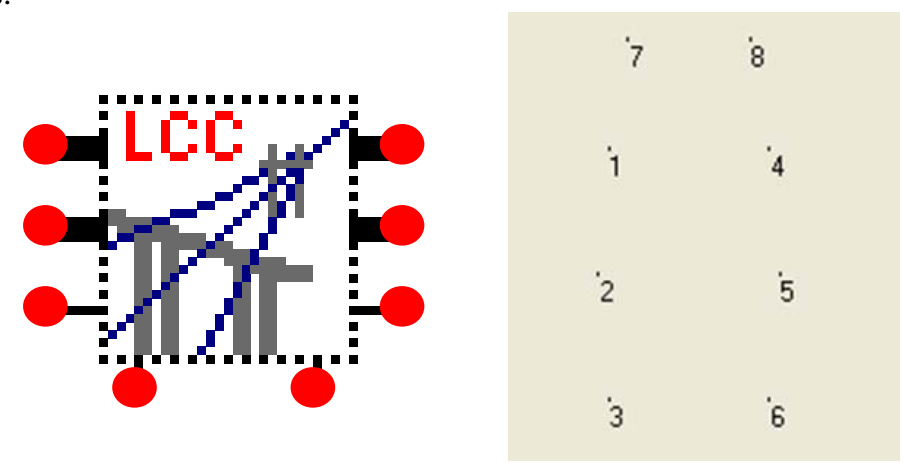

Figure 2. Modeling of transmission line by LCC 


\subsection{Transmission tower}

The tower type of Canal 110kV substation is double circuit transmission tower SZT-35, its structure and parameters are shown in Figure 3.

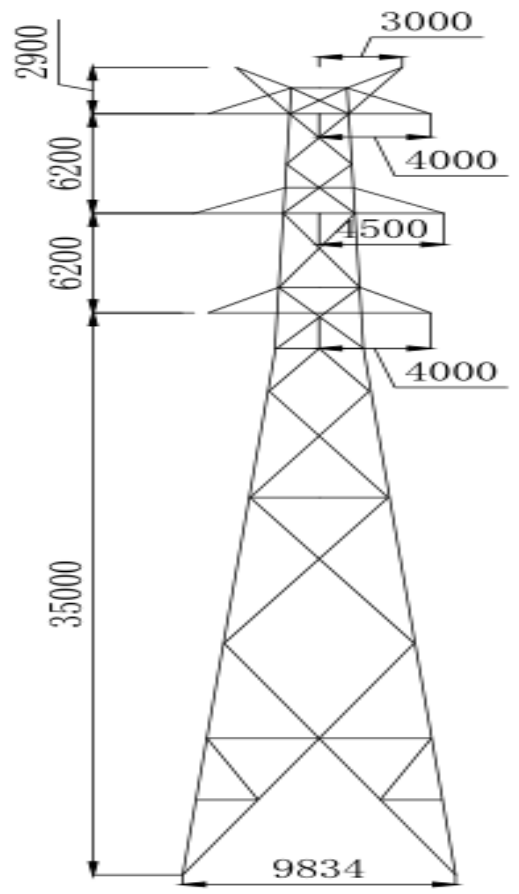

Figure 3. Structure of tower.

When lightning strikes, different tower models will directly affect the propagation characteristics of lightning in the tower, the tower's overhead potential and the flashover time. Tower model experienced a lumped parameter inductor model, a single wave impedance model to a multi-wave impedance model. The early tower less than 40 meters is usually simulated by lumped parameter inductor model. Later, with appearance of high tower, single wave impedance model is proposed to represent propagation characteristics of wave by the wave impedance and propagation velocity. But in fact the wave impedance of tower can not be single, it should be a function of time, so later a multiwave impedance model, each part of the tower represented by different wave impedance is proposed. The multi-wave impedance model is generally used in the calculation of lightning protection domestic and overseas currently [4]. The most representative models of multi-wave impedance model are the lossless line model proposed by Hara and multilayered transmission tower model proposed by Yamada.

Hara lossless line model is adopted in this paper to simulate SZT-35 tower, its characteristic is broken the tower down into the main timber tower, oblique sheet and cross arm three parts, then each unit are respectively simulated by different impedance, the calculation processes of the impedances of each part are as follows[5]:

The main timber tower is calculated as follows:

$$
Z_{T k}=60\left(\ln \frac{2 \sqrt{2} h_{k}}{r_{e k}}-2\right) \quad(k=1,2,3,4)
$$

Where $\mathrm{Z}_{\mathrm{Tk}}$ - wave impedance values of $\mathrm{k}$-th portion of the main timber tower, $\Omega$;

$\mathrm{h}_{\mathrm{k}}$ - $\mathrm{k}$-th cross arm height, $\mathrm{m}$;

$\mathrm{re}_{\mathrm{k}}-\mathrm{k}$-th cross arm at the equivalent radius, $\mathrm{m}$, equivalent radius is calculated as follows: 


$$
r_{e k}=\left\{\begin{array}{l}
\sqrt[8]{2} \cdot\left[\sqrt[3]{r_{T k} \cdot\left(r_{B}^{\prime}\right)^{2}}\right]^{1 / 4} \cdot\left[\sqrt[3]{R_{T k} \cdot\left(R_{B}^{\prime}\right)^{2}}\right]^{3 / 4}(k=1,2,3) \\
\sqrt[8]{2} \cdot\left[\sqrt[3]{r_{T k} \cdot\left(r_{B}\right)^{2}}\right]^{1 / 4} \cdot\left[\sqrt[3]{R_{T k} \cdot\left(R_{B}\right)^{2}}\right]^{3 / 4}(k=4)
\end{array}\right.
$$

Significance of $h_{k}, r_{T k}, R_{T k}$ and $r B, R B$ are shown in Figure 4, whose units are $m$.
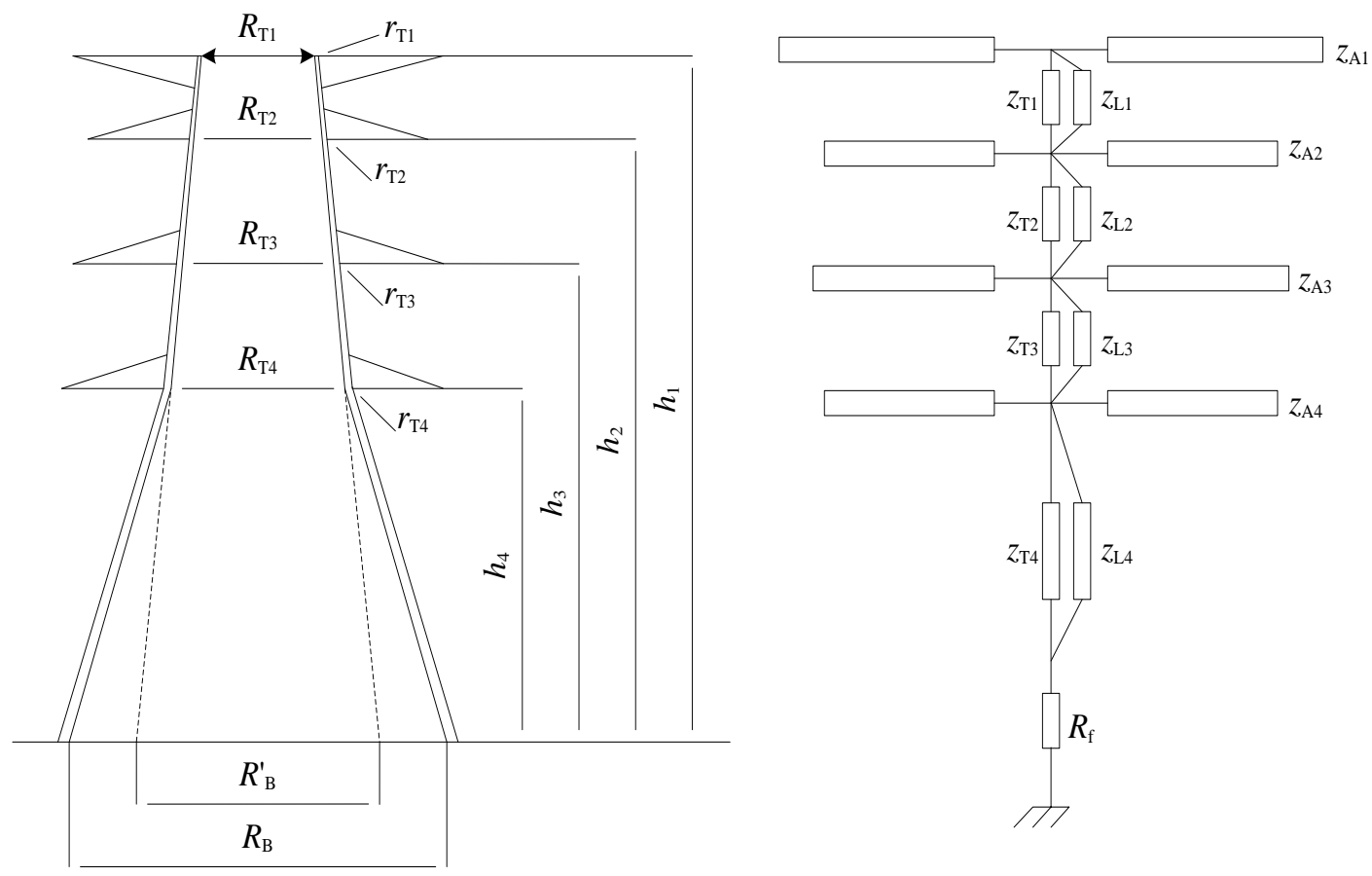

Figure 4. Model of Hara lossless line.

The existence of oblique sheet makes the impedance of tower fell about $10 \%$, so the impedance value of the oblique sheet is generally 9 times the corresponding parts of the main timber tower. Since the impedance of oblique sheet has less impact on the tower, it can be generally ignored in the simulation of tower. The influence of oblique sheet is ignored in this paper.

As an important part of the tower, the cross arm is used to mounting insulator strings and fittings thereby supporting the wire and ground wire, it is generally treated as a normal horizontal conductor in the impedance calculation of cross arm, formula is as follows:

$$
Z_{A k}=60 \ln \frac{2 h_{k}}{r_{A k}} \quad(k=1,2,3,4)
$$

Where $\mathrm{Z}_{\mathrm{Ak}}$ —cross arm impedance values of k-th part, $\Omega$;

$\mathrm{r}_{\mathrm{Ak}}$ - the equivalent radius of $\mathrm{k}$-th cross arm, $\mathrm{m}$.

\section{Lightning withstand level analysis}

The simulation model of the lightning withstand level built in ATPDraw is shown in Figure 5, with irrespective of the operating voltage wires, and the three-phase impedance model adopted in the end of transmission line to eliminate the lightning waves' catadioptric[6,7]. 


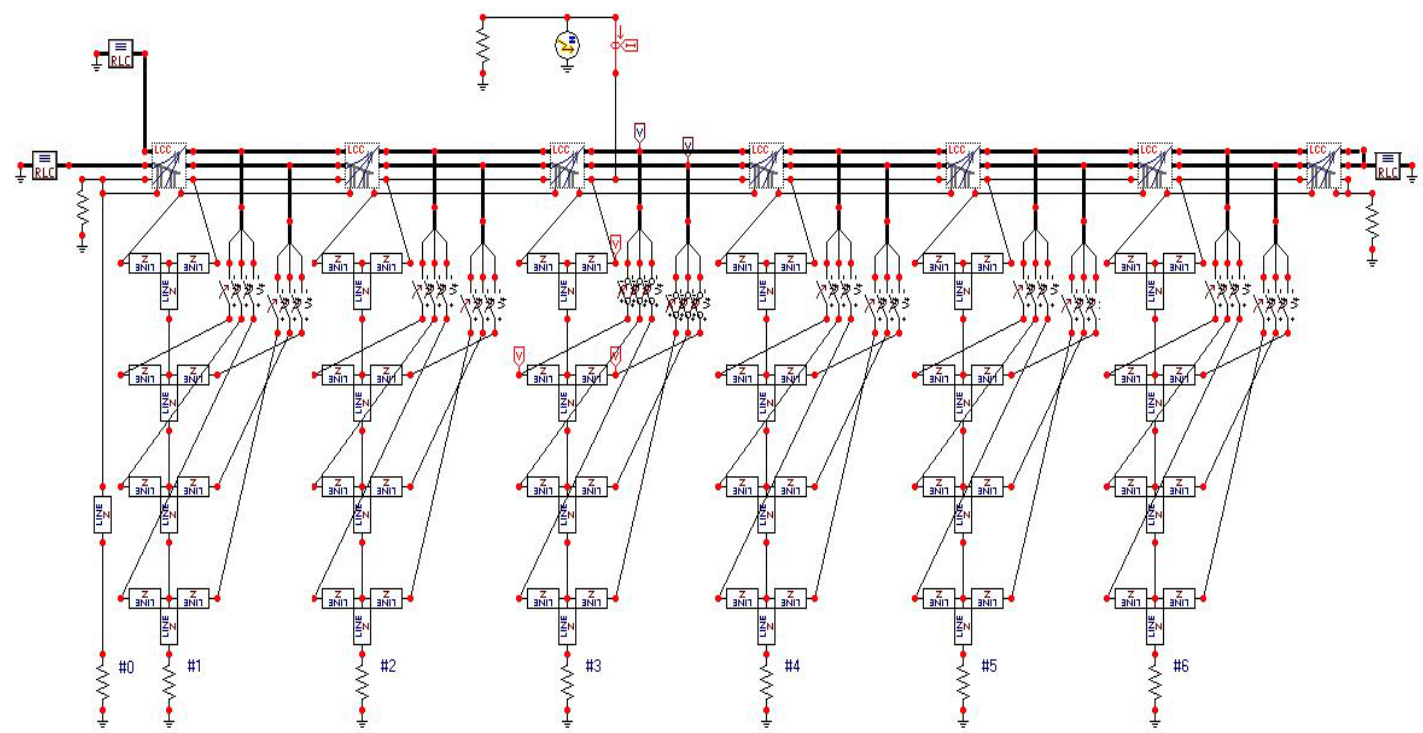

Figure 5. Modeling of lighting fight back withstand level

SZT-35 upper phase's lightning withstands levels of ATP-EMTP simulation analysis method and regulation method is illustrated in Table 1.

Table 1 .lighting fight back withstand level

\begin{tabular}{|c|c|c|}
\hline method & ATP-EMTP simulation method & regulation method \\
\hline lightning withstand level & 52.4 & 51.2 \\
\hline
\end{tabular}

The results of the two methods shows that the two results were similar, lightning withstand level of SZT-35's upper phase is roughly 52kA.

\section{Effect of frequency voltage on flashover}

Frequency voltage on the wire is a random quantity, it has a certain impact on flashover phase distribution when lightning strikes; while the different arrangement of the phase sequence on the same tower also has an impact on the flashover.

\subsection{Same sequence arrangement}

Wires on SZT-35 are arranged in the same sequence, namely circuit I and circuit II are ordered in ABC phase arrangement, as shown in Figure 6. 


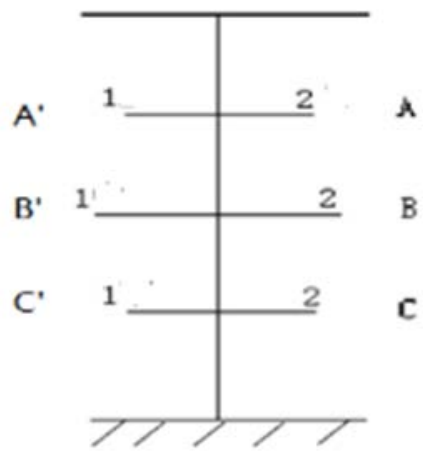

Figure 6. Arrangement of same phase sequence

Considering the impact of the double lines' frequency voltage phase, flashover phase distribution table under the lightning current impact of 60kA is shown in Table 2, the flashover phase is ordered front to back in the table.

Table 2. Distribution of flashover with same phase sequence

\begin{tabular}{|c|c|c|c|c|}
\hline Circuit II & Circuit I $0^{\circ}$ & Circuit I $90^{\circ}$ & Circuit I $180^{\circ}$ & ${\text { Circuit I } 270^{\circ}}^{\circ}$ \\
\hline $0^{\circ}$ & 2middle1 middle & 2 middle & 1 upper & 1 middle2middle \\
\hline $90^{\circ}$ & 1 middle & 2lower2 upper & 1 upper & 1 middle \\
\hline $180^{\circ}$ & 2 upper & 2 upper & 2 upper1 upper & 2upper1middle \\
\hline $270^{\circ}$ & 2 middle1middle & 2middle & 1upper2middle & 2middle1middle \\
\hline
\end{tabular}

It can be seen from the analysis of data in Table 2 that, when the double-circuit transmission lines with the same phase sequence arrangement, the flashover phase of the corresponding operating voltage phase is completely symmetrical. Under the impact of the lightning current, the distribution of the first flashover occurs is: upper phase $43.75 \%$, middle phase $50 \%$, lower phase $6.25 \%$.

\subsection{Opposed sequence arrangement}

Wires on SZT-35 are arranged in the opposed sequence, namely circuit I ordered in CBA phase arrangement, but circuit II ordered in ABC phase arrangement, as shown in Figure 7.

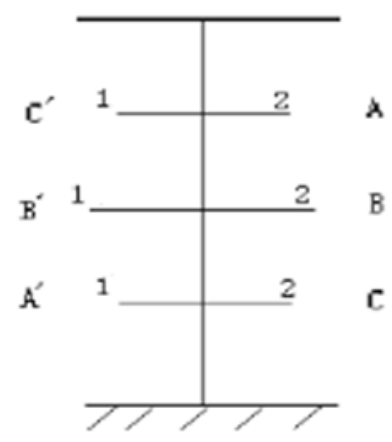

Figure 7. Arrangement of opposed phase sequence.

Considering the impact of the double lines' frequency voltage phase, flashover phase distribution table under the lightning current impact of 60kA is shown in Table 3, the flashover flashover phase is also ordered front to back in the table. 
Table 3. Distribution of flashover phases with opposed phase sequence

\begin{tabular}{|c|c|c|c|c|}
\hline circuit II & Circuit I $0^{\circ}$ & Circuit I $90^{\circ}$ & Circuit I $180^{\circ}$ & ${\text { Circuit I } 270^{\circ}}^{\circ}$ \\
\hline $0^{\circ}$ & 1upper1middle & 1upper2middle & 2middle & 1middle 2middle \\
\hline $90^{\circ}$ & 1middle & 1upper2lower & 1lower2upper & 1middle \\
\hline $180^{\circ}$ & 2upper1upper & 2upper1upper & 2upper1lower & 2upper1middle \\
\hline $270^{\circ}$ & 2middle 1upper & 2middle 1upper & 2middle & 2middle 1middle \\
\hline
\end{tabular}

It can be seen from the analysis of data in Table 3 that, when the double-circuit transmission lines with different phase sequence arrangement, the probability of flashover on cross arm of the same height is different. Similarly, the distribution of the first flashover occurs is: upper phase $43.75 \%$, middle phase $50 \%$, lower phase $6.25 \%$.

Considering the simulation results of same phase sequence and opposed phase sequence, we can know that More than $90 \%$ of the flashover first occurred towers in the upper and middle phases, and opposed phase sequence arrangement effectively reduces the probability of lightning trip of both cross arms in the same height.

\section{Conclusion}

The lighting withstand level is analyzed in this paper by ATP-EMTP, and by comparing to the result of regulation method, verified the correctness of the calculation. At the same time, the impacts of double-loop frequency operating voltage to flashover of same phase sequence and opposed phase sequence are analyzed respectively. The results indict that the majority of first flashover occurred in the upper and middle phases, and the same sequence arranged of double-circuit line is more likely to jump with lightning in the same time. To reduce the hazards of lightning over-voltage, the phase sequence should be arranged to avoid the same tower double-circuit line, and should be properly reinforced insulation levels of the upper and middle phases.

\section{Reference}

1. Yuanchao. A $220 \mathrm{kV}$ outdoor substation lightning invasion wave computational analysis based on ATP-Draw ,D, Shandong: Shandong University(2013)

2. Shi Jidong, Deng $\mathrm{Xu}$, Zhou Hao,et. lightning jumping accident simulation and flashover phase distribution on $220 \mathrm{kV}$ Double Circuit Transmission Lines,J, power construction, 35(1), 5056(2014)

3. Zhuang Qiuyue. $1000 \mathrm{kV}$ substation lightning invasion wave analysis ,D,Beijing Jiaotong University(2010)

4. 4 Zhang remember, Sima Wenxia, Zhang Jin. Lightning Research and Analysis on the tower model ,J, High Voltage Engineering, 32 (7), 93-97( 2006)

5. Nur Zawani, Junainah, Imran, et al. Modelling of $132 \mathrm{kV}$ Overhead Transmission Lines by Using ATP/EMTP for Shielding Failure Pattern Recognition,J, Procedia Engineering , 53, 278287(2013)

6. Pan Xiang, FU Zhengcai. Tower models with double circuit $110 \mathrm{kV}$ tower high tower lightning counterattack overvoltages ,J, Electrical Technology, 6, 1-4( 2012)

7. Yangqiu Xia, Zhu Libo. ATP-EMTP based Transmission Line LIGHTNING performance computing and simulation ,J, electrical switches, 4, 47-50(2010) 